\title{
Side lying during nebulisation can significantly improve apical deposition in healthy adults and adults with mild cystic fibrosis lung disease: a randomised crossover trial
}

\author{
Ruth L. Dentice ${ }^{7^{*}}$, Mark R. Elkins ${ }^{2,3}$, Jordan Verschuer ${ }^{4}$, Stefan Eberl ${ }^{4}$, Genevieve Dwyer ${ }^{5^{*}}$ (D) and Peter T. P. Bye ${ }^{3,6}$
}

\begin{abstract}
Background: In people with and without Cystic Fibrosis (CF), does side lying during nebulisation change: the proportion of the dose loaded in the nebuliser that is deposited in the lungs; the uniformity of deposition throughout the lungs; or the apical drug density as a percentage of the drug density in the remaining lung? Do these effects differ depending on the degree of lung disease present?

Methods: A randomised crossover trial with concealed allocation, intention-to-treat analysis and blinded assessors, involving 39 adults: 13 healthy, 13 with mild CF lung disease ( $F E V_{1}>80 \%$ pred), and 13 with more advanced CF lung disease ( $\mathrm{FEV}_{1}<80 \%$ pred). In random order, $4 \mathrm{~mL}$ of nebulised radioaerosol was inhaled in upright sitting and in alternate right and left side lying at 2-min intervals, for 20 min.

Results: Compared to sitting upright, lung deposition and the uniformity of deposition were not significantly altered by side lying in any of the three groups. In sitting, the density of the deposition was significantly less in the apical regions than in the rest of the lung in all participants. Side lying significantly improved apical deposition in healthy adults (MD, 13\%; 95\% Cl, 7 to 19), and in minimal CF lung disease (MD, 4\%; 95\% Cl, 1 to 7 ) but not in advanced disease (MD, 4\%; 95\% Cl, -2 to 9 ).
\end{abstract}

Conclusion: Alternating between right and left side lying during nebulisation significantly improves apical deposition in healthy adults and in adults with mild CF lung disease, without substantial detriment to overall deposition.

Trial registration: ACTRN12611000674932 (Healthy), ACTRN12611000672954 (CF)

Retrospectively registered 4/7/2011.

Keywords: Cystic fibrosis, Body position, Lung deposition, Physical therapy

\section{Background}

The distribution of deposition of inhaled drugs is influenced by airflow. In sitting, tidal ventilation is preferentially to basal regions [1]. Nebulisation in sitting may under-dose the apical regions [2]. It has been

\footnotetext{
* Correspondence: ruth.dentice@health.nsw.gov.au:

ruth.dentice@sswahs.nsw.gov.au; g.dwyer@westernsydney.edu.au;

G.Dwyer@westernsydney.edu.au

${ }^{1}$ Physiotherapy Department, Royal Prince Alfred Hospital, Sydney, Australia

${ }^{5}$ Physiotherapy Program, Western Sydney University, Sydney, Australia

Full list of author information is available at the end of the article
}

hypothesised that inhalation in alternate side lying will improve homogeneity of drug deposition by dosing each lung (including its apex) when it is dependent [3]. Additionally, many people with Cystic Fibrosis (CF) prefer to nebulise in side lying due to comfort and convenience [4]. A recent study confirmed that the use of an alternate side-lying positioning strategy during inhalation therapy does not prolong nebulisation time [5].

There are however potential disadvantages of a sidelying strategy. Gravitational and biomechanical changes reduce lung volumes and compliance in side lying [6,7].

(c) The Author(s). 2019 Open Access This article is distributed under the terms of the Creative Commons Attribution 4.0 International License (http://creativecommons.org/licenses/by/4.0/), which permits unrestricted use, distribution, and reproduction in any medium, provided you give appropriate credit to the original author(s) and the source, provide a link to the Creative Commons license, and indicate if changes were made. The Creative Commons Public Domain Dedication waiver (http://creativecommons.org/publicdomain/zero/1.0/) applies to the data made available in this article, unless otherwise stated. 
Closing volume of the small airways equals or exceeds functional residual capacity as early as 44 years of age, in recumbent positions $[8,9]$. Side lying can also decrease alertness [10], negatively impacting inspiratory flows and nebuliser technique. Finally, oropharyngeal pooling may increase the proportion of the loaded drug dose being swallowed in side lying compared to upright sitting. Thus any potential benefits of the side-lying strategy may be outweighed if less drug is deposited in the lungs. Investigation of the strategy's effect on the pattern of drug deposition is therefore needed to guide clinical practice.

Progression of CF lung disease reduces both lung elasticity and airflow [11]. Therefore, it is possible that the effect of the side-lying strategy would be different in people with mild versus advanced lung disease. Accordingly the research questions were:

1. In people with and without $\mathrm{CF}$, does side lying during nebulisation change the proportion of the dose loaded in the nebuliser that is deposited in the lungs; the uniformity of deposition throughout the lungs; or the apical drug density as a percentage of the drug density in the remaining lung?

2. Do these effects differ depending on the degree of lung disease present?

\section{Methods}

A randomised crossover trial was undertaken to compare two positioning strategies during nebulised delivery of a radioaerosol on 2 days within 1 week, separated by at least one washout day. Adults with $\mathrm{CF}$ were recruited from the CF Clinic at Royal Prince Alfred Hospital, Sydney, Australia. Potential participants were excluded if they: had received a lung transplant, were colonised with Burkholderia cepacia complex, were not clinically stable; were pregnant; or had hepatomegaly, hepatosplenomegaly, current intestinal obstruction, or significant malignant, neurological or musculoskeletal comorbidities. Adults with CF were recruited in two strata: mild and advanced CF. Mild CF was defined as stable normal lung function with an $\mathrm{FEV}_{1}$ and $\mathrm{FVC}$ greater than $80 \%$ predicted and a normal $\mathrm{FEV}_{1}: \mathrm{FVC}$ ratio, plus minimal upper lobe damage evident on chest radiograph or, if available, on computerised tomographic (CT) scan of the lungs. Advanced $\mathrm{CF}$ was defined as stable abnormal (moderate to severe) lung function defined as $\mathrm{FEV}_{1}$ less than $80 \%$ predicted, with evidence of upper lobe damage on chest radiograph or, if available, on CT scan of the lungs. A third group of healthy adults with an $\mathrm{FEV}_{1}$ greater than $80 \%$ predicted were recruited from the staff of the hospital.

Testing appointments were scheduled at least $4 \mathrm{~h}$ after standard CF morning medications, and not within $1 \mathrm{~h}$ of a meal. On both days, participants performed spirometry $^{1}$ in standing according to American Thoracic Society criteria [12]. Healthy participants and participants with mild CF lung disease were required to demonstrate an $\mathrm{FEV}_{1}$ greater than $80 \%$ predicted that day. Participants with $\mathrm{CF}$ were required to have maintained their $\mathrm{FEV}_{1}$ within $10 \%$ of their best value recorded as an outpatient within the preceding 6 months that day. Participants were then randomised, by flipping a coin, to one of two positioning regimens for their first day: upright sitting, which was maintained throughout the nebulisation period of $20 \mathrm{~min}$; or alternate side lying, with alternation between left and right sides every 2 minutes during the nebulisation period of $20 \mathrm{~min}$.

In an earlier study by our group [5], the two-minute turning regimen and the 20-min total inhalation period were shown to be appropriate to completely nebulise the loaded dose and to ensure equal total nebuliser output while in each side lying position. During the study inhalation periods, all participants were requested to adopt their allocated position and inhale slowly, with a slightly greater volume than at rest, maintaining a lip seal throughout. Inhalation breathing pattern was minimally coached to reflect the spontaneous nebulisation that occurs during unsupervised self-management. When participants returned for their second study day, they adopted the other positioning regimen. Participants with CF were requested to keep their medication regimen, chest physiotherapy and exercise constant during their entire study participation period.

\section{Outcome measures}

\section{Radioaerosol inhalation}

The standard study inhalation was $4 \mathrm{~mL}$ of normal saline mixed with $500 \mathrm{MBq}$ of technetium-99 m diethylene triamine penta-acetic acid $\left({ }^{99 \mathrm{~m}} \mathrm{Tc}\right.$-DTPA), delivered by an LC Star jet nebuliser (Pari, Germany) ${ }^{2}$ with mouthpiece and nose clip. Delivery of the aerosol was 20 min in duration on each occasion, which was sufficient to deliver a total activity of about $100 \mathrm{MBq}$. The nebuliser was shielded with a flexible, lead, wraparound shield. A Y-piece was fitted to the mouthpiece and a filter applied to the expiratory arm to trap exhaled radiation. The nebuliser was driven with $6 \mathrm{~L} /$ min of air via the hospital wall supply and a calibrated flow meter.

The nebuliser with tubing, Y-piece and filter were weighed on an electronic balance ${ }^{3}$ before and after the $4 \mathrm{~mL}$ dose was loaded; and after the delivery period to allow estimation of the dose delivered to the participant and the residual volume in the nebuliser. The positioning methods adopted during inhalation are pictured in Fig. 1. 

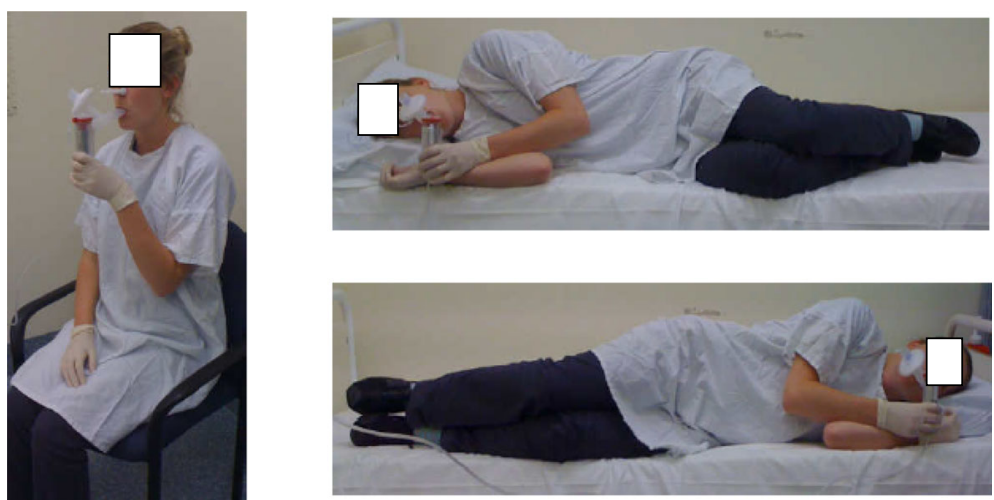

Fig. 1 Positioning methods adopted during inhalation with the LC Star jet nebuliser (LC plus nebuliser, Pari, Hamburg, Germany) with mouthpiece, filter and nose clip. Alternate side lying involved dropping the legs over the side of the bed to turn through upright and reposition on the other side every 2 minutes, when instructed by the supervising investigator. (Image with permission)

\section{Imaging of deposition and blinded analysis}

At the completion of the nebulisation, the participant was positioned supine and head first under a triplehead gamma camera ${ }^{\mathrm{d} 4}$. The camera performed a 20 min deposition scan, incorporating simultaneous emission and transmission acquisitions using a dynamic SPECT imaging protocol well established by our research group [13-16]. Data from the transmission scan were used for attenuation correction of the emission data and also served to segment the threedimensional margin of the lung fields in order to objectively assess the regional deposition of radioaerosol within the lungs (Fig. 2).

The scan also distinguished regional body deposition: oropharynx versus lungs versus stomach. These data were re-coded before being passed to the investigators to ensure blinding of the body position adopted during each study. For a total delivered activity of $100 \mathrm{MBq}$, for which approximately 50 to $70 \%$ deposits in the lungs, the effective dose to the subject equates to 1.0 to $1.5 \mathrm{mSv}$ per inhalation, giving a total effective dose per participant of 2 to 3 $\mathrm{mSv}$ for the complete study. This is safely below the annual radiation dose constraint of $5 \mathrm{mSv}$ per individual in any year for adult volunteers in biomedical research, as mandated by the NSW Radiation Control Regulation [17]. Research procedures were approved by the Ethics Committees of the Sydney Local Health District (RPAH Zone) and the Radiation Safety Officer before commencement. All participants provided written informed consent prior to participating in this study.

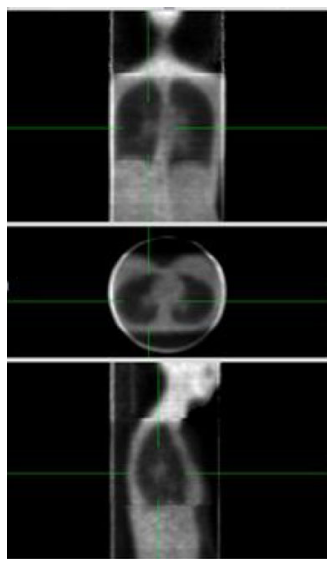

1

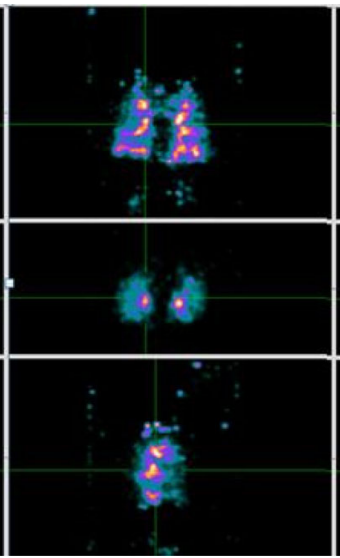

2

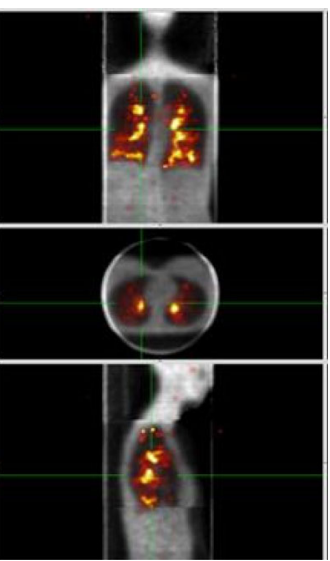

3

Fig. 2 Representative images from one participant during simultaneous emission-transmission dynamic SPECT imaging of radioaerosol deposition: 1. The transmission data is primarily used for attenuation correction of the emission data 2. The emission data records the deposition of the inhaled radioaerosol 3. The transmission data is also used to segment the three-dimensional margin of the lung fields in order to determine the regional distribution of the deposited radioaerosol within the lungs 


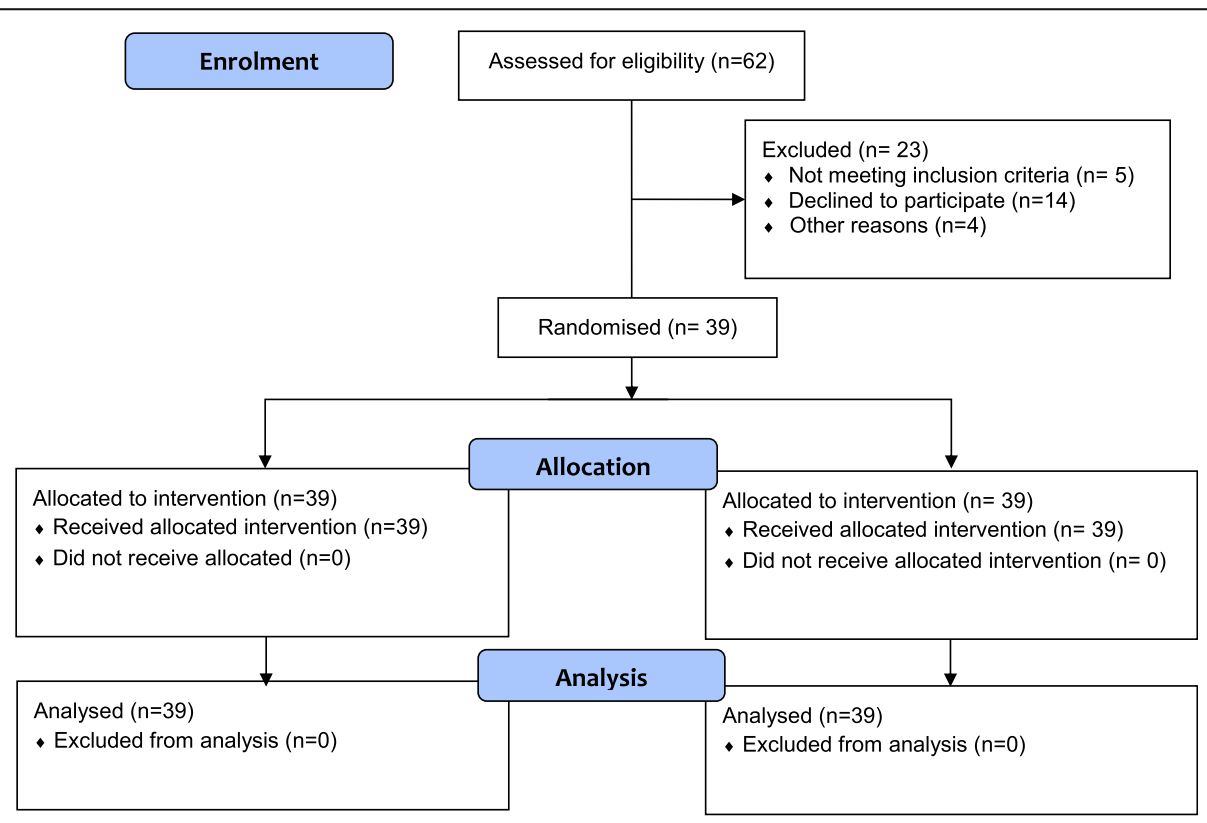

Fig. 3 Consort flow diagram

\section{Data analysis}

The 3-dimensional map of the lung fields was divided into unit volumes (voxels). The amount of radioactivity in each voxel was calculated. The deposition fraction was calculated as the amount of radioactivity in the lung fields divided by the amount of radioactivity in the nebuliser before inhalation, with correction for radioactive decay. The standard deviation of the radioactivity across all voxels within the margins of the lung fields was used as an index of variability of the pattern of deposition for each participant (variability index). Lower values represent better uniformity of deposition. The ratio of apical:non-apical deposition of radioactivity was determined by the mean number of counts per voxel in the apical one third of the lung field divided by the mean number of counts per voxel in the basal two thirds of the lung field.

The prospectively registered primary outcome was the variability index described above. Our data from initial deposition scans in repeat mucociliary clearance studies in healthy participants indicates that the standard deviation of the uniformity index is 0.18 [18]. In the absence

Table 1 Study participants' characteristics

\begin{tabular}{llll}
\hline Characteristic & $\begin{array}{l}\text { Healthy } \\
(n=13)\end{array}$ & $\begin{array}{l}\text { Mild CF } \\
(n=13)\end{array}$ & $\begin{array}{l}\text { Advanced CF } \\
(n=13)\end{array}$ \\
\hline $\begin{array}{l}\text { Age (y) mean } \pm \text { SD } \\
\text { (range) }\end{array}$ & $28 \pm 5$ & $27 \pm 7$ & $30 \pm 6$ \\
$(23$ to 40$)$ & $(19$ to 41$)$ & $(22$ to 41$)$ \\
$\begin{array}{l}\text { FEV } 1 \% \text { pred.) mean } \pm \text { SD } \\
\text { (range) }\end{array}$ & $104 \pm 9$ & $92 \pm 10$ & $48 \pm 17$ \\
Gender (M:F) & $(92$ to 119$)$ & $(80$ to 115$)$ & $(25$ to 78$)$ \\
\hline
\end{tabular}

of an existing threshold, we nominated that a $15 \%$ improvement in the uniformity index would be the minimum difference that would make the side-lying strategy worthwhile. Adopting a significance level of 0.05 and power of $80 \%$, it was determined, using a commercial sample size calculator ${ }^{5}$, that we would require a sample size of 13 in each of the three groups.

Paired t-tests were used to compare the effect of the two positioning regimens on the deposition fraction, variability index, and ratio of apical: non-apical deposition of radioactivity. Where the data were not normally distributed, a Mann-Whitney test replaced the paired ttest. Correlations between percent predicted $\mathrm{FEV}_{1}$ and deposition patterns were investigated with linear regression. Pair-wise independent t-tests were used to compare subgroups with respect to the effect of the positioning on the variability of deposition. All t-tests were reported as a mean difference with a $95 \%$ confidence interval.

\section{Results}

\section{Flow of participants through the study}

Thirty-nine participants were recruited and completed the study, 13 in each group as outlined in the flowchart in

Table 2 Percentage of the loaded nebuliser dose that deposits in the lungs (mean \pm SD), for the three participant groups in sitting and side lying

\begin{tabular}{llll}
\hline & $\begin{array}{l}\text { Healthy } \\
(\%)\end{array}$ & $\begin{array}{l}\text { Mild CF } \\
(\%)\end{array}$ & $\begin{array}{l}\text { Advanced CF } \\
(\%)\end{array}$ \\
\hline Sitting & $11 \pm 6$ & $16 \pm 5$ & $11 \pm 5$ \\
Side lying & $11 \pm 6$ & $17 \pm 5$ & $11 \pm 3$ \\
\hline
\end{tabular}


Table 3 The mean $( \pm S D$ ) variability in lung deposition measured as the standard deviation in counts of radioactivity per unit lung volume in sitting and side lying for the three participant groups, with representative scans of the group participants in sitting

\begin{tabular}{llll}
\hline SD counts per voxel & Healthy & Mild CF & Advanced CF \\
\hline Sitting & $1294 \pm 920$ & $1920 \pm 851$ & $2229 \pm 774$ \\
Side lying & $1250 \pm 981$ & $1980 \pm 370$ & $1892 \pm 486$
\end{tabular}

Fig. 3 and Table 1. For individual participant data, see Additional file 1.

Does side lying change the proportion of the dose loaded in the nebuliser that is deposited in the lungs?

In sitting, there was significantly greater lung deposition in mild CF compared to healthy participants mean difference (MD, 5\%; 95\% CI, 1 to 9). There was also significantly greater lung deposition in mild compared to advanced CF participants (MD, 5\%; 95\% CI, 1 to 9). The proportion of the dose loaded in the nebuliser that was deposited in the lungs was unaltered by side lying in any group Table 2 . The distribution of drug deposition to lung, orophranyx and stomach was also unaltered by side-lying strategy (analyses not shown but raw data is available in the Additional file 1).

\section{Does side lying change the uniformity of deposition throughout the lungs?}

The uniformity index increased with increasing lung disease. The variability of the deposition was not significantly improved or worsened by the side-lying strategy in any of the three groups. The mean variability in lung deposition for each group in the two positioning regimens is presented in Table 3 below with representative scans obtained after the aerosol delivery in sitting in Fig. 4.
Does side lying change the apical drug density?

If drug density was entirely uniform then the apical density per unit volume would be exactly the same as the drug density in the remaining lung per unit volume (100\%). In sitting, the density of the deposition was significantly reduced in the apical regions in all groups, to approximately $40 \%$ of the density in the non-apical regions. The side-lying strategy significantly improved apical deposition in the healthy adults to $49 \pm 14 \%$ (MD, $13 \%$; $95 \% \mathrm{CI}, 7$ to 20 ), and in the adults with minimal CF lung disease to $47 \pm 7 \%$ (MD, $4 \%$; $95 \% \mathrm{CI}, 1$ to 7 ). The mean effect of the side-lying strategy in adults with advanced disease was similar, increasing from $41 \pm 20 \%$ to $45 \pm 21 \%$ with side lying, but the variability was greater so this was not statistically significant (95\% CI, -2 to 9 ) Table 4.

\section{Correlations between change in apical deposition and \% predicted $\mathrm{FEV}_{\mathbf{1}}$}

The change in apical deposition in response to the repositioning from upright to side lying for nebulisation in relation to percent predicted $\mathrm{FEV}_{1}$ is represented in Fig. 5. There was no correlation between the change in apical deposition in response to the repositioning from upright to side lying for nebulisation and percent predicted $\mathrm{FEV}_{1}\left(R^{2}=0.067\right)$.

\section{Discussion}

The percentage of the loaded nebuliser dose that deposited in the lungs was low for all participants, 11 to $16 \%$ are consistent with previous and current studies of jet nebulisers $[2,19,20]$. Healthy participants had significantly lower lung deposition than participants with mild CF in both positioning regimens. Participants with CF were very familiar with nebulised therapies in comparison to healthy naive participants who reported that $20 \mathrm{~min}$ of inhalation on a nebuliser was more challenging than they expected. The distribution of drug deposition to lung, orophranyx and stomach was unaltered by side-lying strategy.

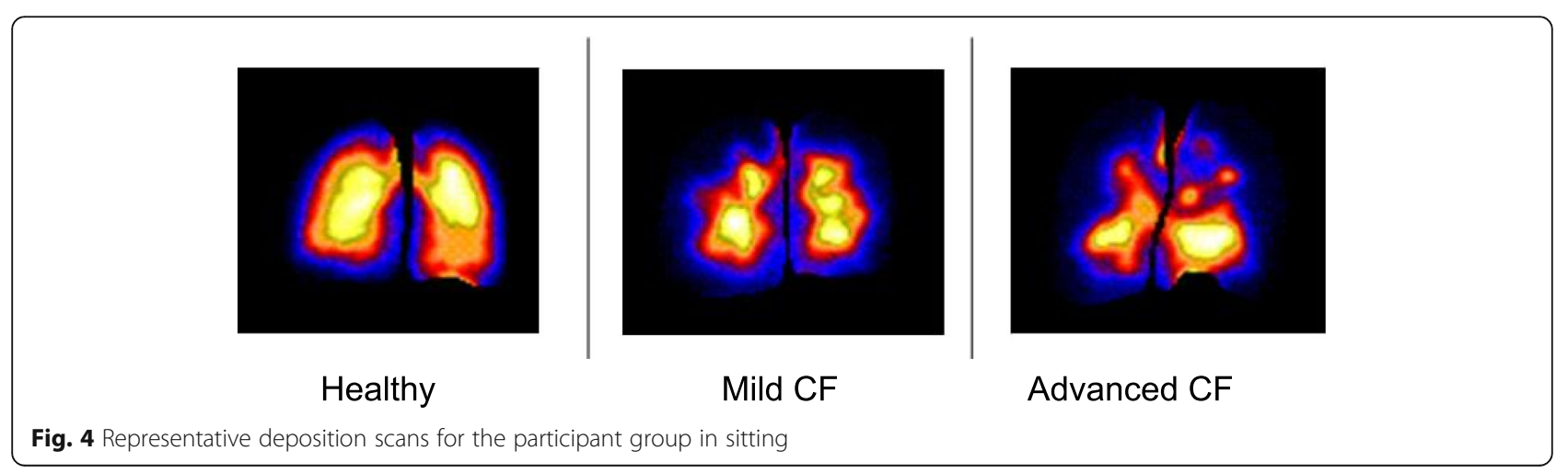


Table 4 The apical drug density per unit lung volume as a percentage of the drug density per unit lung volume in the remaining lung; for the three participant groups in sitting and side lying with the mean difference (\%) and 95\% confidence interval between the two positioning strategies

\begin{tabular}{llll}
\hline$\%$ & Healthy & Mild CF & Advanced CF \\
\hline Sitting & $36 \pm 11$ & $43 \pm 8$ & $41 \pm 20$ \\
Side lying & $49 \pm 14$ & $47 \pm 7$ & $45 \pm 21$ \\
Mean Difference & 13 & 4 & 4 \\
$95 \%$ Cl & (7 to 19) & (1 to 7) & (-2 to 9) \\
\hline
\end{tabular}

In sitting, adults with advanced CF had almost twice as much variability in lung drug deposition compared to healthy adults of similar age. With increasing lung disease there is increasing variability in lung deposition of a nebulised drug. This finding is consistent with previous work involving deposition scanning in this patient population [3, 4, 21-23]. The variability of deposition was not substantially altered by side lying in either group. Participants with advanced CF demonstrated the greatest response with a MD in the variability index of 337 ( $95 \%$ CI, -186 to 860 ). This equates to a $7 \%$ change, which is half that of our proposed minimum clinically worthwhile difference of $15 \%$; nevertheless, the positive trend provides further reassurance that taking a nebuliser in side lying does not substantially compromise drug deposition.

Statistically the side-lying positioning strategy can improve apical deposition. Our best estimate of the effect is a positive one in all three participant groups (Healthy: 13\% better (95\%CI: 7 to 19) Mild CF: $4 \%$ better (95\%CI: 1 to 7 ) Advanced CF: $4 \%$ better (95\%CI: -2 to 9). It is difficult to estimate the clinical impact of this small shift of $4 \%$ towards greater apical deposition in CF participants over the course of multiple nebulised drug doses. Permitting people with CF to have the flexibility to nebulise in side lying may improve treatment adherence in patients who prefer this regimen. The effect of regular use of this positioning regimen could be further examined in a longitudinal trial.

The side-lying strategy was only effective at reversing the deficiency in apical deposition in the subgroups of participants who had well preserved lung function. This suggests that the side-lying strategy may be more helpful in children with $\mathrm{CF}$, or in respiratory conditions where lung function is well preserved, such as pneumocystis pneumonia [24].Additionally, the delivery rate of inhaled medications should be further investigated in mesh and adaptive delivery nebulisers and with drugs of greater viscosity.

\section{Conclusion}

There is no negative impact on lung deposition if adults with CF nebulise in alternate side lying. Adults with $C F$ have almost twice as much variability in the density of nebulised drug deposition across the lung fields compared to healthy adults, which is unaltered with inhalation in side lying. Positioning in side lying can improve apical deposition in healthy lungs and to a lesser extent in mild CF lung disease. Given many patients prefer to nebulise in side lying due to comfort and convenience, permitting nebulisation in side lying may improve treatment adherence without adversely affecting deposition, provided side lying on each side is given equal time.

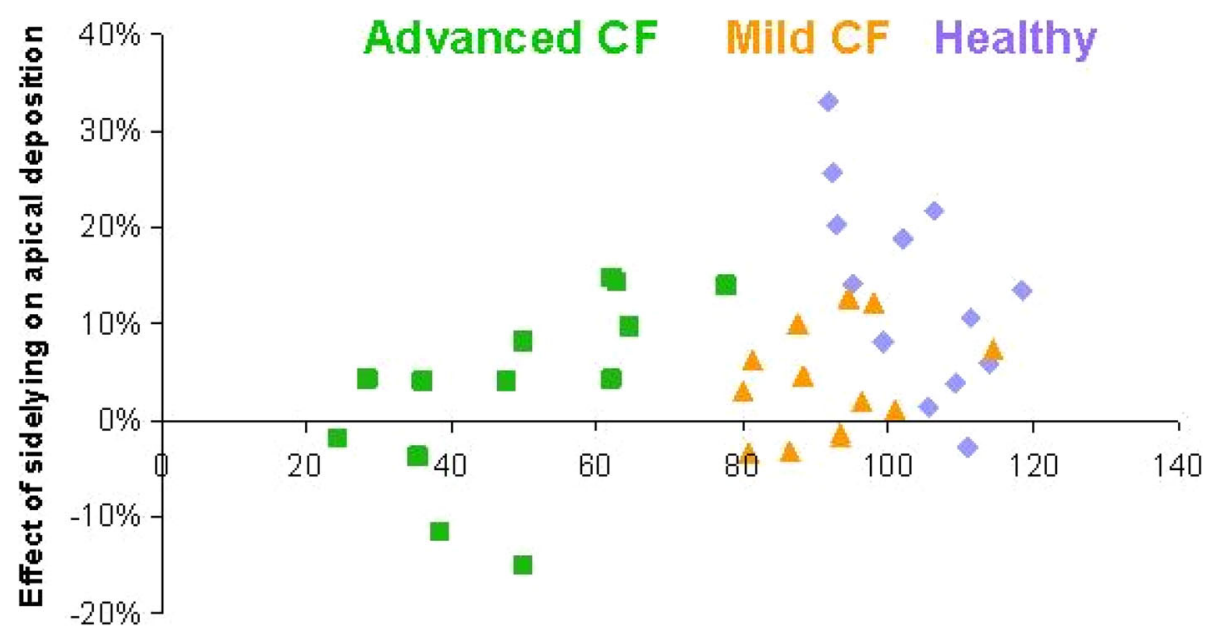

\% Predicted FEV1

Fig. 5 The change in apical deposition in response to the repositioning from upright to side lying for nebulisation. The 13 participants with advanced CF are depicted in green, mild CF in orange and healthy in purple 


\section{Endnotes}

${ }^{1}$ Easy-One, NDD Medical Technologies, Andover, USA

${ }^{2}$ LC plus nebuliser, Pari, Hamburg, Germany

${ }^{3}$ 1206MP Scale, Sartorius, Cambridge, UK

${ }^{4}$ Trionix XLT Triple Head Gamma Camera, Trionix, Twinsburg, USA

${ }^{5}$ PS Power \& Sample Size Calculator, Visual Components, Lake Orion, USA.

\section{Additional file}

Additional file 1: Individual participant data (XLSX $18 \mathrm{~kb})$

\begin{abstract}
Abbreviations
${ }^{99 m}$ Tc-DTPA: Technetium-99 m diethylene triamine penta-acetic acid; CF: Cystic Fibrosis; FEV ${ }_{1}$ : Forced expiration in the first second; FVC: Forced vital capacity; MD: Mean difference
\end{abstract}

\section{Acknowledgements}

The authors are grateful to the participants at Royal Prince Alfred Hospital for their involvement.

\section{Authors' contributions}

RLD, MRE, JV, SE, GD and PTPB contributed substantially to the study conception, study design, data analysis and interpretation of data. RLD and MRE were responsible for data acquisition and take responsibility for the integrity of the data and the accuracy of the data analysis, including and especially any adverse effects. All authors were involved in either the drafting and/or critical revision of the manuscript, have read and given approval for submitted manuscript. All authors are agreeable to be accountable for all aspects of the work presented.

\section{Funding}

This study was supported by an Australian Physiotherapy Association PRF Grant (S09-014) but this agency had not direct input or competing interests into the conduct of the study.

\section{Availability of data and materials}

The datasets used and/or analysed during the current study are available from the corresponding author on reasonable request.

\section{Ethics approval and consent to participate}

The Sydney Local Health District (RPAH Zone) Ethics Committee approved this study (X09-0017/18, HREC/09/RPAH/25). All participants gave written informed consent before data collection began and also consented to publication of the de-identified data.

\section{Consent for publication}

Consent has been obtained in written form from the individual in Fig. 1 for inclusion of this material in this publication, as confirmed by the authors.

\section{Competing interests}

The authors declare that they have no competing interests.

\section{Author details}

'Physiotherapy Department, Royal Prince Alfred Hospital, Sydney, Australia. ${ }^{2}$ Centre for Education \& Workforce Development, Sydney Local Health District, Sydney, Australia. ${ }^{3}$ Sydney Medical School, University of Sydney, Sydney, Australia. ${ }^{4}$ Department of Molecular Imaging, Royal Prince Alfred Hospital, Sydney, Australia. ${ }^{5}$ Physiotherapy Program, Western Sydney University, Sydney, Australia. ${ }^{6}$ Department of Respiratory Medicine, Royal Prince Alfred Hospital, Sydney, Australia.
Received: 8 January 2019 Accepted: 25 June 2019

Published online: 16 July 2019

\section{References}

1. Amis TC, Jones HA, Hughes JM. Effect of posture on inter-regional distribution of pulmonary perfusion and VAVQ ratios in man. Respir Physiol. 1984;56(2):169-82.

2. Laube BL, Links JM, LaFrance ND, Wagner HNJ, Rosenstein BJ. Homogeneity of bronchopulmonary distribution of $99 \mathrm{mTc}$ aerosol in normal subjects and in cystic fibrosis patients. Chest. 1989:95(4):822-30

3. Laube BL, Jashnani R, Dalby RN, Zeitlin PL. Targeting aerosol deposition in patients with cystic fibrosis: effects of alterations in particle size and inspiratory flow rate. Chest. 2000;118(4):1069-76.

4. Wilson DM, Burniston E, Parkin MA, Smye S, Robinson P, Littlewood J. Improvement of nebulised antibiotic delivery in cystic fibrosis. Arch Dis Child. 1999;80(4):348-52.

5. Dentice RL, Elkins MR, Dwyer GM, Bye PTP. The use of an alternate side lying positioning strategy during inhalation therapy does not prolong nebulisation time in adults with cystic fibrosis: a randomised crossover trial. BMC Pulm Med. 2018; 18(1):3.

6. Hough A. The effect of posture on lung function. Physiotherapy. 1984;70:101-4

7. Castile R, Mead J, Jackson A, Wohl ME, Stokes D. Effects of posture on flow volume curve configuration in normal humans. J Appl Physiol. 1982;53:1175-83.

8. Leblanc P, Ruff F, Milic-Emili J. Effects of age and body position on airway closure in man. J Appl Physiol. 1970;28:448-51.

9. McCarthy DS, Spencer R, Greene R, Milic-Emili J. Measurement of 'closing volume' as a simple and sensitive test for early detection of small airway disease. Am J Med. 1972:52:747-53.

10. Hahn-Winslow E. Cardiovascular consequences of bed rest. Heart Lung. 1985:14:236-46

11. Elkins M, Bye P. Mucociliary clearance and cystic fibrosis. In: Hamid Q, Shannon J, Martin J, editors. Physiologic basis of respiratory disease. New York: B. Decker; 2005. p. 417-28.

12. American Thoracic Society. Standardization of spirometry: 1994 update. Am J Resp Crit Care Med. 1995;152:1107-36.

13. Eberl S, Daviskas E, Constable C, Young I. Aerosol deposition and clearance measurement: a novel technique using dynamic SPET. Eur J Nucl Med Mol Imaging. 2001;28(9):1365-72.

14. Eberl S, Chan HK, Daviskas E. SPECT imaging for Radioaerosol deposition and clearance studies. J Aerosol Med. 2006;19(1):8-20.

15. Glover W, Chan HK, Eberl S, Daviskas E, Anderson S. Lung deposition of mannitol powder aerosol in healthy subjects. J Aerosol Med. 2006;19(4):522-32.

16. Glover W, Chan HK, Eberl S, Daviskas E, Verschuer J. Effect of particle size of dry powder mannitol on the lung deposition in healthy volunteers. Int J Pharm. 2008;349(1):314-22

17. Radiation Control Regulation NSW legislation wbsite. 2013.

18. Brown JS, Zeman KL, Bennett WD. Regional deposition of coarse particles and ventilation distribution in healthy subjects and patients with cystic fibrosis. J Aerosol Med. 2001;14(4):443-54

19. Laube BL, Geller DE, Lin T-C, Dalby RN, Diener-West M, Zeitlin PL. Positive expiratory pressure changes aerosol distribution in patients with cystic fibrosis. Respir Care. 2005;50(11):1438-44.

20. Pritchard JN, Hatley RH, Denyer J, Hollen DV. Mesh nebulizers have become the first choice for new nebulized pharmaceutical drug developments. Ther Deliv. 2018;9(2):121-36

21. Fauroux B, Itti E, Pigeot J, Isabey D, Meignan M, Ferry G, Lofaso F, Willemot J-M, Clement A, Harf A. Optimization of Aerosol Deposition by Pressure Support in Children with Cystic Fibrosis: An Experimental and Clinical Study. Am J Respir Crit Care Med. 2000;162(6):2265-2271.

22. Robinson M, Regnis JA, Bailey DL, King M, Bautovich GJ, Bye PT. Effect of hypertonic saline, amiloride, and cough on mucociliary clearance in patients with cystic fibrosis. Am J Resp Crit Care Med. 1996;153(5):1503-9.

23. Robinson M, Hemming AL, Regnis JA, et al. Effect of increasing doses of hypertonic saline on mucociliary clearance in patients with cystic fibrosis. Thorax. 1997:52(10):900-3.

24. O'Doherty MJ, Thomas SH, Page CJ, Bradbeer C, Nunan TO, Bateman NT. Does inhalation in the supine position increase deposition in the upper part of the lung? Chest. 1990:97:1343-8.

\section{Publisher's Note}

Springer Nature remains neutral with regard to jurisdictional claims in published maps and institutional affiliations. 